\title{
Competing mortality in patients diagnosed with bladder cancer: evidence of undertreatment in the elderly and female patients
}

\author{
A P Noon ${ }^{1}$, P C Albertsen ${ }^{2}$, F Thomas ${ }^{1}$, D J Rosario ${ }^{1}$ and J W F Catto ${ }^{*}, 1$ \\ ${ }^{1}$ The Academic Urology Unit and Institute for Cancer Studies, G Floor, The Medical School, University of Sheffield, Beech Hill \\ Road, Sheffield S10 2JF, UK and ${ }^{2}$ Division of Urology, University of Connecticut Health Center, Farmington, CT 06030, USA
}

Background: Bladder cancer (BC) predominantly affects the elderly and is often the cause of death among patients with muscleinvasive disease. Clinicians lack quantitative estimates of competing mortality risks when considering treatments for BC. Our aim was to determine the bladder cancer-specific mortality (CSM) rate and other-cause mortality (OCM) rate for patients with newly diagnosed BC.

Methods: Patients $(n=3281)$ identified from a population-based cancer registry diagnosed between 1994 and 2009. Median follow-up was 48.15 months (IQ range 18.1-98.7). Competing risk analysis was performed within patient groups and outcomes compared using Gray's test.

Results: At 5 years after diagnosis, 1246 (40\%) patients were dead: 617 (19\%) from BC and 629 (19\%) from other causes. The 5-year BC mortality rate varied between 1 and $59 \%$, and OCM rate between 6 and $90 \%$, depending primarily on the tumour type and patient age. Cancer-specific mortality was highest in the oldest patient groups. Few elderly patients received radical treatment for invasive cancer ( $52 \%$ vs $12 \%$ for patients $<60$ vs $>80$ years, respectively). Female patients with high-risk non-muscle-invasive BC had worse CSM than equivalent males (Gray's $P<0.01$ ).

Conclusion: Bladder CSM is highest among the elderly. Female patients with high-risk tumours are more likely to die of their disease compared with male patients. Clinicians should consider offering more aggressive treatment interventions among older patients.

Bladder cancer (BC) is the fourth most common male malignancy worldwide with 297300 new cases and 112300 death in 2008 (Jemal et al, 2011). The majority of these tumours are urothelial cell carcinomas (UCC), and clinical, pathological and molecular data suggest two discrete disease phenotypes: low- and high-grade disease (Catto et al, 2009). Most tumours arise following exposure to either cigarette smoking or occupational carcinogens (Freedman et al, 2011; Noon et al, 2012). Consequently, BC is most prevalent in industrialised populations and many affected patients also suffer from respiratory or cardiovascular disease, as well as other malignancies. Carcinoma of the lung and bladder often coexist owing to their shared aetiology (del Rey et al, 2010). Bladder cancer is more common in older patients and this may affect cancerspecific survival (Walters et al, 2009). Although BC has a higher incidence in male patients, mortality is proportionally higher in female patients (Mungan et al, 2000).

Patients and clinicians base treatment decisions on a variety of factors: anticipated prognosis, a patient's fitness for treatment and 
a patient's likely life expectancy. Although various molecular, histological and patient factors can be employed to predict clinical outcomes (Youssef and Lotan, 2011), these tools usually do not account for the competing mortality risk posed by other diseases. For example, most analyses employ Kaplan-Meier methods to predict survival. Unfortunately, this approach evaluates only one outcome event: cancer-specific mortality (CSM), other-cause mortality (OCM) or overall mortality. To assess survival where mortality events compete, it is more appropriate to calculate a cumulative incidence function (CIF). For this approach, censored data are partitioned based on the probability of failure between the two competing events (Scrucca et al, 2007).

Given the limited data available concerning competing mortality in patients with BC (Messing et al, 2009), we analysed competing mortality risks for patients with newly diagnosed UCC of the bladder. We compared outcomes across patient populations to obtain information to improve clinical decision-making.

\section{MATERIALS AND METHODS}

Patient and tumours. The Royal Hallamshire Hospital is the sole urological provider for the city of Sheffield, UK (population $800000)$. There is relatively little social mobility in this industrial city; thus, patients with urological disease within this community remain under the care of this department for the duration of their care (Sheffield City Council, 2012). To determine the long-term outcomes of patients with $\mathrm{BC}$, we created a database of all patients diagnosed with this disease at our institution between 1 January 1994 and 31 December 2009. We matched pathological features, hospital billing data and death certification records (obtained from the Trent Cancer Registry), as detailed elsewhere (Linton et al, 2012; Thomas et al, 2013). We reviewed case-notes for patients with missing data or conflicting codes and $2 \%$ of all cases (chosen at random).
To ensure data integrity, two workers separately merged data streams to create parallel databases, which were then compared and differences resolved by committee. Deaths were classified as CSM or OCM according to the main attributable certified cause of death (parts 1a or 1b on the UK death certificate; Rink et al, 2012) and supported by selected case-notes (e.g. pathological or radiological evidence of metastases/tumour progression, palliative treatment before death).

Selection criteria. All adult patients with primary BC were selected for inclusion $(n=3634)$. Those referred from other institutions for secondary opinions, those with histology other than UCC and those with inadequate follow-up ( $<6$ months) $(n=238)$ were excluded. We also excluded cases in which the cause of death was unclear from the death certificate (e.g. renal failure with coexisting BC) and not supported by post-mortem evidence $(n=115)$.

Statistical analysis. Patients were stratified into four age groups $(<60,60-69,70-79$ and $>80$ years) at diagnosis. Tumours were assigned histological staging and grading according to the 1973 WHO and TNM classifications, and stratified according to mortality risk: low-risk, non-muscle-invasive BC (MIBC) (grades 1 and 2, pTa), high-risk, non-MIBC (all high-grade, non-muscleinvasive tumours, including any with CIS, and all tumours with lamina propria invasion (pT1)) and MIBC (stage T2 or greater).

The Kruskal-Wallis analysis and $\chi^{2}$ tests were used to compare medians and proportions, respectively. Survival analyses with respect to time were plotted using the Kaplan-Meier method. Statistical tests were performed using SPSS (Vsn. 19.0; SPSS Inc., Chicago, IL, USA) or Prism (Vsn. 5.0; GraphPad Software, San Diego, CA, USA). All statistical tests were two-tailed and significance was defined as $\mathrm{P}<0.05$. Competing risk analysis was performed by calculating the CIF as described (Scrucca et al, 2007) using R (Vsn. 1.43; The R Foundation for Statistical Computing;

\begin{tabular}{|c|c|c|c|c|c|c|}
\hline & Total cohort & $<60$ years & 60-69 years & 70-79 years & $80+$ years & $\boldsymbol{P}$-value \\
\hline No. of patients (\%) & $3281(100)$ & 487 (15) & $850(26)$ & $1180(36)$ & $764(23)$ & \\
\hline \multicolumn{7}{|l|}{ Sex } \\
\hline $\begin{array}{l}\text { Male (\%) } \\
\text { Female (\%) }\end{array}$ & $\begin{array}{l}2368(72) \\
913(28)\end{array}$ & $\begin{array}{l}336(69) \\
151(31)\end{array}$ & $\begin{array}{l}640(75) \\
210(25)\end{array}$ & $\begin{array}{l}870(74) \\
310(26)\end{array}$ & $\begin{array}{l}522(68) \\
242(32)\end{array}$ & $<0.01$ \\
\hline \multicolumn{7}{|l|}{ Age } \\
\hline $\begin{array}{l}\text { Median } \\
\text { IQ Range }\end{array}$ & $\begin{array}{c}72.6 \\
64.6-79.4\end{array}$ & $\begin{array}{c}54.7 \\
21.3-57.7\end{array}$ & $\begin{array}{c}65.8 \\
63.1-68.0\end{array}$ & $\begin{array}{c}74.9 \\
72.5-77.3\end{array}$ & $\begin{array}{c}83.8 \\
81.8-86.9\end{array}$ & $<0.001$ \\
\hline \multicolumn{7}{|l|}{ Tumour group } \\
\hline $\begin{array}{l}\text { Low risk (\%) } \\
\text { High risk (\%) } \\
\text { MIBC (\%) }\end{array}$ & $\begin{array}{l}1440(44) \\
955(29) \\
886(27)\end{array}$ & $\begin{array}{l}242(50) \\
111(23) \\
134(28)\end{array}$ & $\begin{array}{l}367(43) \\
254(30) \\
229(27)\end{array}$ & $\begin{array}{l}519(44) \\
348(30) \\
313(27)\end{array}$ & $\begin{array}{l}312(41) \\
242(32) \\
210(27)\end{array}$ & 0.03 \\
\hline \multicolumn{7}{|c|}{ Follow-up (months) } \\
\hline $\begin{array}{l}\text { Median } \\
\text { IQ range }\end{array}$ & $\begin{array}{c}31.8 \\
10.9-75.8\end{array}$ & $\begin{array}{c}44.3 \\
14.1-114.3\end{array}$ & $\begin{array}{c}42.5 \\
13.1-92.8\end{array}$ & $\begin{array}{c}32.3 \\
11.6-75.7\end{array}$ & $\begin{array}{c}20.4 \\
7.4-48.9\end{array}$ & $<0.001$ \\
\hline \multicolumn{7}{|l|}{ Status at 5 years } \\
\hline $\begin{array}{l}\text { Alive (\%) } \\
\text { CSM (\%) } \\
\text { OCM (\%) } \\
\text { Censored (\%) }\end{array}$ & $\begin{array}{l}1080(33) \\
617(19) \\
629(19) \\
955(29)\end{array}$ & $\begin{array}{c}208(43) \\
55(11) \\
54(11) \\
170(35)\end{array}$ & $\begin{array}{l}334(39.3) \\
134(15.8) \\
104(12.2) \\
278(32.7)\end{array}$ & $\begin{array}{l}398(34) \\
226(19) \\
238(20) \\
318(27)\end{array}$ & $\begin{array}{l}140(18) \\
202(26) \\
233(31) \\
189(25)\end{array}$ & $<0.001$ \\
\hline
\end{tabular}


http://www.R-project.org). Comparison of specific CIFs was performed using Gray's test (Gray, 1988). Competing mortality data models were plotted using a smoothed nonlinear fit to the events in Prism.

\section{RESULTS}

Patients and survival. We identified 3281 patients suitable for analysis (Table 1). The cohort comprised 2368 (72\%) male and 913 (28\%) female patients. The median age at presentation was 72.6 years (IQ range 64.6-79.5). Muscle-invasive tumours were present in $886(27 \%)$ and high-risk tumours in $955(29 \%)$ patients at diagnosis. The tumour phenotypes changed with age. While lowrisk tumours were more common in younger patients $(50 \%$ and $41 \%$ of tumours in the youngest and oldest cohorts, respectively), high-risk tumours increased with age (23\% vs $32 \%$, respectively, $P=0.03$ ). The median follow-up for the population was 48.2 months (IQ range 18.1-98.7) and decreased with rising age $(P<0.001)$. For patients who survived 5 years $(n=1080)$, the median follow-up was 100.4 months (IQ range 76.9-134.6). At 10 years, 372 patients were alive, 665 had died of BC and 895 had died of another cause. Outcome analyses evaluated the cumulative survival from diagnosis of the entire cohort with respect to allcause mortality (ACM) and CSM (Figure 1). In general, ACM increased progressively as patients aged, in contrast to CSM in which most $\mathrm{BC}$ deaths occurred within 3 years of diagnosis.
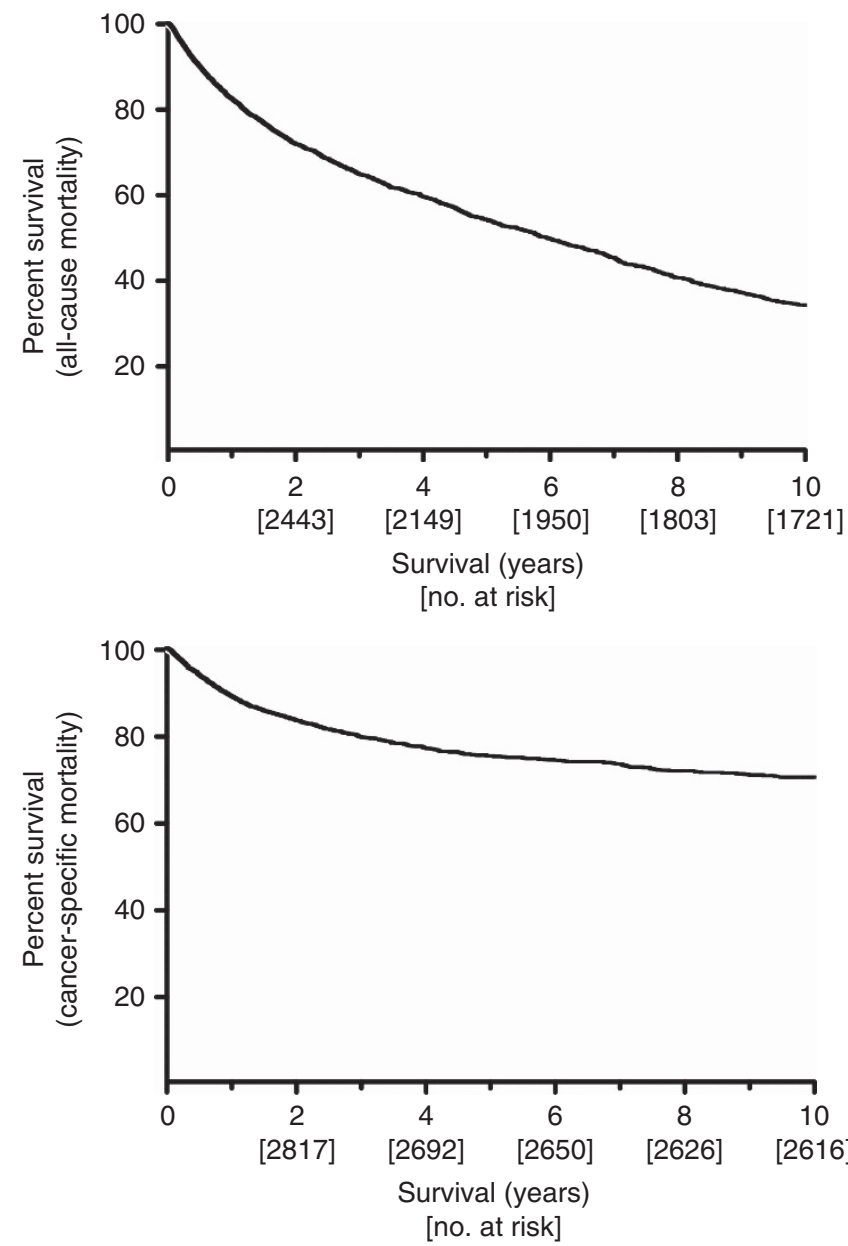

Figure 1. All-cause mortality (top) and disease-specific mortality (bottom) are plotted using the Kaplan-Meier method. The number remaining at risk is shown below the time intervals.
Competing risks. To evaluate 5-year OCM and CSM, cumulative incidence curves were generated for the cohort and stratified according to age at diagnosis and tumour risk. The summary data is provided in Table 2 and presented in Figure 2. Estimated CSM varied from $0.9 \%$ (95\% CI: $0.2-3.1$ ) to $59.3 \%$ (95\% CI: $51.4-66.4$ ) and estimated OCM from 5.0\% (95\% CI: 2.4-8.9) to $43.8 \%$ (95\% CI: 37.3-50.1), depending on the patient age and tumour type. As expected, CSM increased proportionally with tumour risk $(5.4 \%$ vs $24.4 \%$ vs $49.7 \%$, for low-risk, high-risk and muscle-invasive disease, respectively, $P<0.001)$. In contrast, OCM did not vary with tumour risk for the majority of patients (i.e. those aged 60-79 years (62\% of the population)).

Outcomes with respect to patient age. Comparisons across patients harbouring the three tumour subgroups revealed that CSM increased directly with age (Gray's, $P<0.001$ ). This was also true for OCM, except for patients with MIBC. While the findings of higher OCM with age were expected, we were surprised that CSM was so strongly associated with age. To investigate possible explanations for this finding, we compared treatments administered to patients in the high-risk and MIBC cohorts. As reported previously (Thomas et al, 2012), intravesical BCG for high-risk disease was used less frequently in the oldest patients (administered to $38 \%$ of patients aged $<60$ years, $36 \%$ for patients aged $60-69$ years, $37 \%$ for patients aged $70-79$ years and $31 \%$ for those aged $>80$ years, trend not significant). Older patients were also less likely to undergo transurethral re-resection of the bladder within 3 months of initial resection (diagnosis) $(31 \%$ for patients aged $<60$

Table 2. Estimated 5-year CSM and OCM for the 12 patient groups

\begin{tabular}{|c|c|c|c|c|}
\hline $\begin{array}{l}\text { Age } \\
\text { group }\end{array}$ & \multicolumn{3}{|c|}{ Tumour group } & \multirow[t]{2}{*}{$P$-value } \\
\hline & Low risk & High risk & MIBC & \\
\hline \multicolumn{5}{|c|}{$<60$ years } \\
\hline $\begin{array}{l}\text { CSM } \\
(95 \% \mathrm{Cl})\end{array}$ & $0.9(0.2-3.1)$ & $11.6(6.1-19.1)$ & $41.0(31.1-50.7)$ & $<0.001$ \\
\hline $\begin{array}{l}\text { OCM } \\
(95 \% \mathrm{Cl})\end{array}$ & $5(2.4-8.9)$ & $13.2(7.1-21.1)$ & $30.6(21.9-39.8)$ & $<0.001$ \\
\hline \multicolumn{5}{|c|}{$60-69$ years } \\
\hline $\begin{array}{l}\text { CSM } \\
(95 \% \text { Cl) }\end{array}$ & $3.6(1.9-6.2)$ & $17.2(12.3-22.8)$ & $48.1(40.3-55.5)$ & \\
\hline $\begin{array}{l}\text { OCM } \\
(95 \% \mathrm{Cl})\end{array}$ & $12.7(9.1-16.8)$ & $15.5(10.8-20.9)$ & $20.5(14.7-27.1)$ & $=0.41$ \\
\hline \multicolumn{5}{|c|}{ 70-79 years } \\
\hline $\begin{array}{l}\text { CSM } \\
(95 \% \mathrm{Cl})\end{array}$ & $6.8(4.6-9.5)$ & $24.3(19.5-29.4)$ & $48.3(42.0-54.4)$ & \\
\hline $\begin{array}{l}\text { OCM } \\
(95 \% \mathrm{Cl})\end{array}$ & $21.5(17.7-25.7)$ & $24.8(19.9-30.0)$ & $30.2(22.5-36.1)$ & $=0.77$ \\
\hline \multicolumn{5}{|l|}{$80+$} \\
\hline $\begin{array}{l}\text { CSM } \\
(95 \% \mathrm{Cl})\end{array}$ & $8.4(5.4-12.2)$ & $37.7(30.9-44.5)$ & $59.3(51.4-66.4)$ & $<0.001$ \\
\hline OCM & $43.8(37.3-50.1)$ & $38.2(31.3-45.1)$ & $30.8(23.7-38.2)$ & $<0.001$ \\
\hline P CSM & $<0.001$ & $<0.001$ & $<0.001$ & \\
\hline P OCM & $<0.001$ & $<0.001$ & $=0.152$ & \\
\hline
\end{tabular}



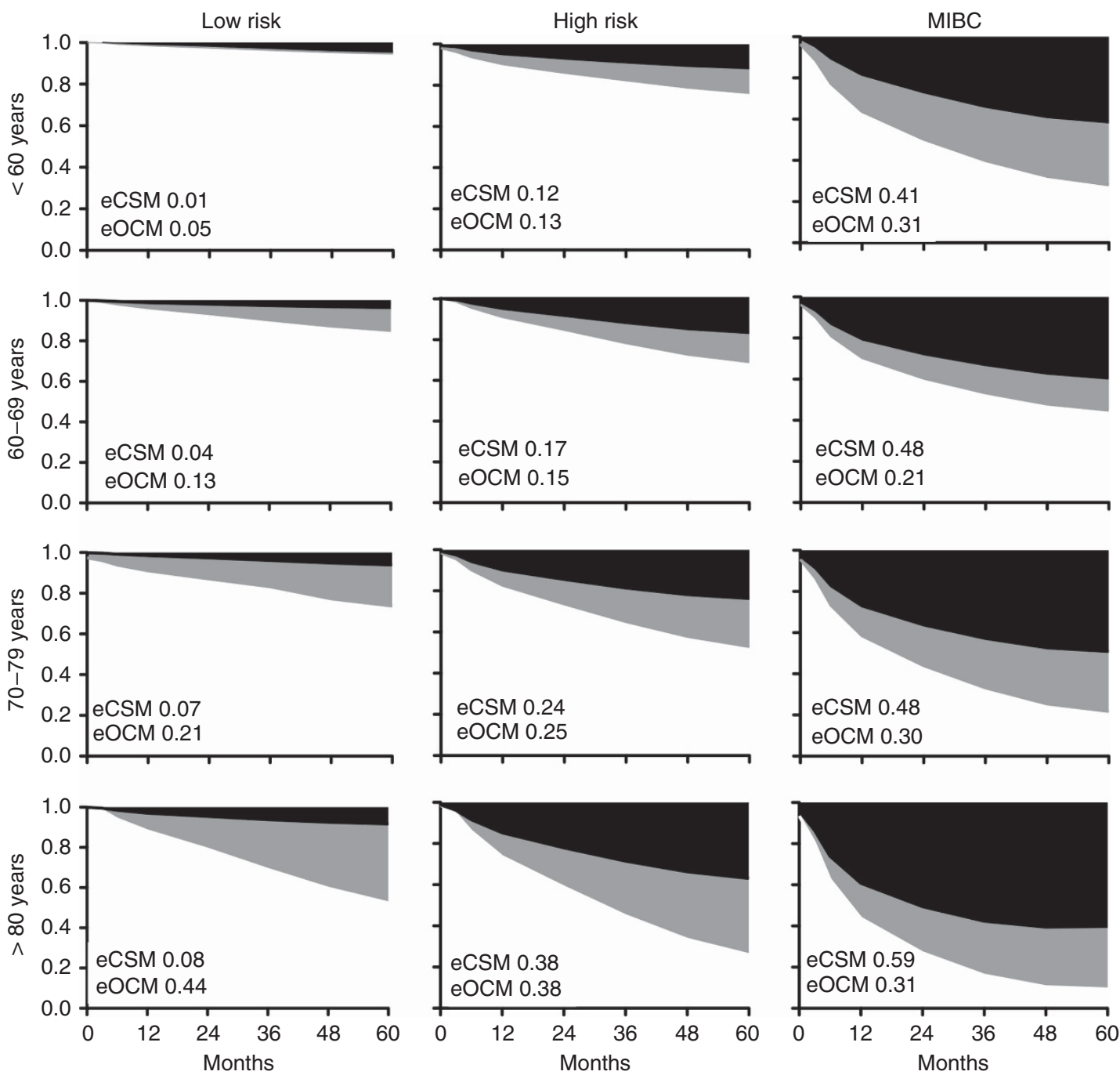

Figure 2. The 5-year competing mortality data models for patients stratified by primary tumour (columns) and age at diagnosis (rows). Black shaded area = estimated CSM (eCSM) and grey shaded area = estimated OCM (eOCM) - plotted as 1 minus the sum of CSM and OCM.

years, $27 \%$ for patients aged $60-69$ years, $24 \%$ for patients aged 70-79 years and in $19 \%$ of those aged $>80$ years, trend not significant). For patients with MIBC, radical cystectomy or radical radiotherapy was used in $52 \%$ of patient's aged $<60$ years, $50 \%$ aged $60-69$ years, $34 \%$ aged $70-79$ years and in only $12 \%$ of those aged $>80$ years $\left(\chi^{2} P<0.001\right.$; Supplementary Table 1$)$.

Patient age did not explain changes in CSM for patients with low-risk BC. To understand this finding, we reviewed the frequency of grade 1 disease by age cohort. We found that grade 1 (well-differentiated) tumours comprised 152 of 242 (63\%), 193 of 366 (53\%), 259 of $519(50 \%)$ and 176 of 312 (44\%) of low-risk cancers for patients aged $<60,60-69,70-79$ and $>80$ years, respectively. Therefore, the proportion of grade 2 tumours increased with age, rising from 37 to $56 \%$ through the four age groups. Older patients appear to present with increasingly highgrade disease $\left(\chi^{2} P<0.001\right)$.

Outcomes for male and female patients. Data suggest worse outcomes for female patients with BC when compared with male patients (Mungan et al, 2000). This may be due to more aggressive tumours at presentation or the higher average age achieved by female patients. To investigate this finding, we analysed the cumulative incidences of OCM and CSM with respect to gender (Figure 3). At 5 years, there were no significant differences in the estimated male and female OCM and CSM for patients with lowrisk or MIBC disease. For patients with high-risk tumours, there was no difference in estimated OCM between male and female patients, but female patients were more likely to die from BC than male patients $(\mathrm{CSM}=32 \%$ vs $22 \%$, respectively, Gray's $P<0.01)$. Male and female patients with high-risk disease were equally likely to receive BCG therapy (male $36 \%$ vs female $32 \%(\mathrm{P}=0.4)$ ).

Diagnoses of non-CSM. We tabulated the specific diseases responsible for OCM to understand the non-BC deaths in our cohort (Table 3). Other diseases, such as pulmonary and cardiac, accounted for the majority of deaths (470 of $629(75 \%))$. Analysis by age and tumour group (Supplementary Table 2) showed that the youngest patients with MIBC had more deaths due to other malignancies $(n=19)$ when compared to their peers with low- and high-risk disease $\left(n=4\right.$ and 6 respectively, $\left(\chi^{2} P<0.001\right)$.

\section{DISCUSSION}

To date, this is the largest report regarding competing mortality in patients diagnosed with the spectrum of $\mathrm{BC}$. We found that outcomes for patients with newly diagnosed BC vary between excellent for young patients with low-risk disease (95\% survival at 5 years) to extremely poor for older patients with muscle-invasive disease (10\% survival at 5 years). CSM increased with advancing stage and worsening cellular differentiation. Cancer-specific mortality was highest in older patients because older patients 

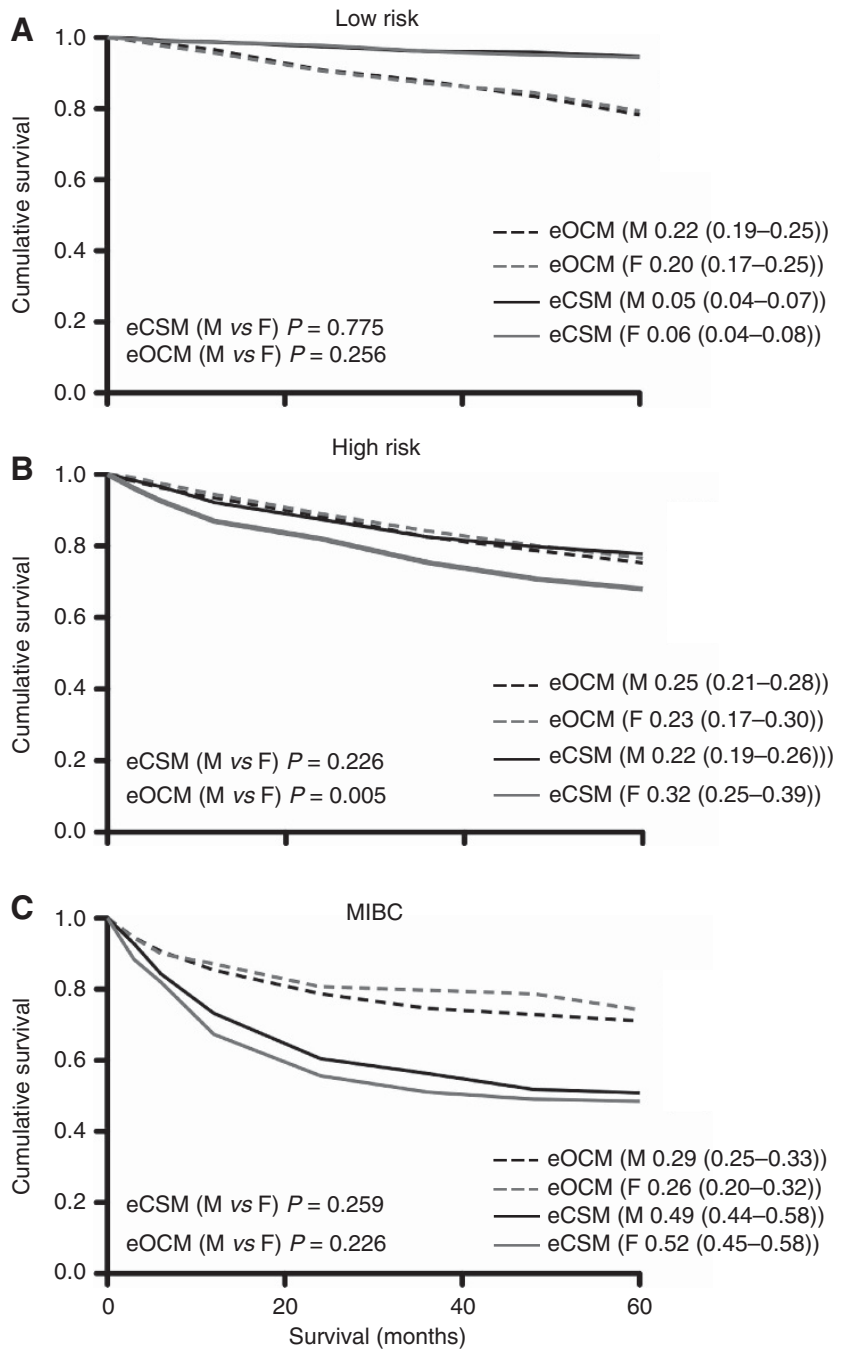

Figure 3. Estimated cumulative incidence curves for OCM and CSM as competing events for male and female patients with (A) low-risk tumours ( $n=1027$ males vs $n=413$ females), (B) high-risk tumours ( $n=743$ males vs $n=212$ females) and (C) MIBC ( $n=598$ males vs $n=288$ females).

had a higher prevalence of high-risk tumours and were less likely to undergo radical curative treatment (Nielsen et al, 2007) or receive intravesical therapies when compared with younger patients. While out data support this association, we could not exclude disease-related factors (such that older patients develop more aggressive cancers). In contrast, OCM did not vary with tumour type for the majority of patients (i.e. the $62 \%$ aged between 60 and 79 years). Among older patients where CSM was highest, OCM was lowest. Among younger patients, OCM increased with worsening tumour type. Patients with advanced tumours were more likely to die of a competing mortality when compared to patients with low-risk cancers. As this finding appeared counterintuitive, we examined specific causes of OCM within these populations. As shown in Table 3, younger patients with MIBC were more likely to die of other malignancies when compared to those with low-risk cancers. Possible explanations include higher carcinogen exposures(Sturgeon et al, 1994) necessary for invasive carcinogenesis in young patients, treatment-related mortality (e.g. post-radical therapy) or the misclassification of the certified cause of death.

Our finding that female patients with high-risk disease have a higher CSM than their male counterparts is novel and will need further investigation. We believe that the observation is real, given that we evaluated 212 female patients and 743 male patients with this disease. Palou et al (2012) in a retrospective analysis of 146 patients with primary stage T1G3 NMIBC treated with BCG found female gender to be a poor prognostic factor for CSM. As no gender difference in CSM was noted in the invasive $\mathrm{BC}$ cohort (the published literature contains conflicting reports on gender differences following cystectomy; Mungan et al, 2000; Youssef and Lotan, 2011; Otto et al, 2012), it is interesting to speculate about the causes of our specific observation among patients with high-risk disease. Potential explanations include that: (1) female patients respond less well to BCG immunotherapy than male patients (as suggested by Palou et al, 2012), (2) female bladders maybe less well staged at resection (female bladders are typically thinner walled than obstructed male bladders and so more prone to understaging muscle-invasive disease) or (3) there are longer delays in the time to diagnosis for female patients (as irritative bladder symptoms or haematuria in female patients are initially treated as infections or detrusor over activity, before further investigation) (Johnson et al, 2008).

Our data complement and enhance the few previous manuscripts reporting competing mortality in patients with UCC. Messing et al (2009) quantified competing events in 509 male patients diagnosed with BC in Wisconsin in 1988 according to four age and three tumour cohorts.(Scrucca et al, 2007). We found higher rates of OCM among patients with prostate cancers and lower rates of CSM among the elderly and in men with high-risk tumours. Given that overall mortality rates were similar to the men in our series, these differences may reflect the lack of female patients in the Wisconsin series or potential misclassifications of the cause of death in some patients. Lughezzani et al (2011) reported competing mortality in 11260 patients following radical cystectomy using data from the Surveillance, Epidemiology and End Results registries. In this cohort of advanced tumours (89\% were muscle invasive), CSM dominated survival outcomes, so that OCM contributed to only $8-27 \%$ of deaths at 5 years. The highest rates of OCM were seen in the oldest patients with the least invasive tumours (pT1 and pT2). Inman et al (2009) reported competing mortality in 168 patients with UCC of the upper urinary tract. At a median of 6 years after surgery, around $1 / 3$ of patients had died from competing risks and around $40 \%$ from urothelial cancer. Tumour stage and grade were the strongest predictors of the latter. Our study did not stratify patients using existing comorbidity scores. Mayr et al (2012) evaluated five different performance indices and found all were associated with cancer-independent mortality, but none with CSM.

Our study's strength derives from its population-based study design and the uniform management of affected patients by urooncologists (Moore, 1995). Furthermore, the low migration rate from this population ensures that a high proportion of patients were followed to death or closure of data collection (Sheffield City Council, 2012). Our data are representative of a Caucasian Northern European population, and as such can be extrapolated elsewhere into Northern Europe, North America and Australasia to enhance clinical decision-making. Our study's weakness results primarily from the observational study design rather than prospectively collected data. Another difficulty in interpreting our data arises from the heterogeneity of treatment options, which may have resulted in a biasing of the CSM (less fit patients may have been declined this treatment).

This study allows clinicians to estimate and compare the risks of CSM and OCM for patient with recently diagnosed bladder carcinoma. We found that older patients had a significantly worse cause-specific mortality than their younger colleagues despite similar risks of OCM. Female patients have a higher risk of CSM when compared with their male counterparts. While the former 


\begin{tabular}{|c|c|c|c|c|c|c|}
\hline & $\begin{array}{l}\text { Male, } \\
\text { n (\%) }\end{array}$ & $\begin{array}{c}\text { Female, } \\
\text { n (\%) }\end{array}$ & $\begin{array}{c}<60 \text { years, } \\
\text { n (\%) }\end{array}$ & $\begin{array}{c}\text { 60-70 years, } \\
n(\%)\end{array}$ & $\begin{array}{c}\text { 70-80 years, } \\
n(\%)\end{array}$ & $\begin{array}{c}80+\text { years, } \\
n(\%)\end{array}$ \\
\hline Neoplastic & $145(32)$ & $55(33)$ & $29(54)$ & $49(47)$ & $73(31)$ & $49(21)$ \\
\hline Pulmonary & $119(26)$ & $36(21)$ & $10(19)$ & $14(14)$ & $54(23)$ & 77 (33) \\
\hline Cardiac & $85(19)$ & $30(18)$ & $8(15)$ & $17(16)$ & $49(21)$ & $41(18)$ \\
\hline Cerebrovascular & $21(5)$ & $12(7)$ & $2(4)$ & $5(5)$ & $12(5)$ & $14(6)$ \\
\hline GI (non-malignant) & $20(4)$ & $7(4)$ & $3(6)$ & $5(5)$ & $13(6)$ & $6(3)$ \\
\hline Old age & $11(2)$ & $12(7)$ & - & - & $4(2)$ & $19(8)$ \\
\hline Renal & $15(3)$ & $5(3)$ & - & $3(3)$ & $10(4)$ & $7(3)$ \\
\hline Infective & $14(3)$ & $5(3)$ & $2(4)$ & $4(4)$ & $6(3)$ & $7(3)$ \\
\hline Vascular & $16(4)$ & $2(1)$ & - & $2(2)$ & $10(4)$ & $6(3)$ \\
\hline Haematological (non-malignant) & $6(1)$ & $5(3)$ & - & $5(5)$ & $3(1)$ & $3(1)$ \\
\hline Neurologic (non-vascular) & $4(1)$ & - & - & - & $3(1)$ & $1(0)$ \\
\hline Intentional & $2(0)$ & - & - & - & $1(0)$ & $1(0)$ \\
\hline Unknown & $2(0)$ & - & - & - & - & $2(1)$ \\
\hline Total & 460 & 169 & 54 & 104 & 238 & 233 \\
\hline
\end{tabular}

may be due to more conservative treatment of aggressive BCs in the elderly, the reasons for gender disparities remain unclear and should be the subject of further research.

\section{ACKNOWLEDGEMENTS}

JWFC had full access to all of the data in the study. JWFC and APN take full responsibility for the integrity of the data and the accuracy of the data analysis. JWFC was supported by a GSK Clinician Scientist fellowship and project grants from Yorkshire Cancer Research, Sheffield Hospitals Charitable trust and the European Union (European Community's Seventh Framework Programme. Grant Numbers: FP7/2007-2013 and HEALTH-F22007-201438). Ethical approval: SSREC 00/083.

\section{REFERENCES}

Catto JW, Miah S, Owen HC, Bryant H, Myers K, Dudziec E, Larre S, Milo M, Rehman I, Rosario DJ, Di Martino E, Knowles MA, Meuth M, Harris AL, Hamdy FC (2009) Distinct microRNA alterations characterize high- and low-grade bladder cancer. Cancer Res 69(21): 8472-8481.

del Rey J, Placer J, Vallmanya F, Pujol N, Prat E, Miro R, Gelabert A (2010) Are patients with non-muscle-invasive bladder cancer a suitable population for a lung cancer screening trial? BJU Int 106(1): 49-52.

Freedman ND, Silverman DT, Hollenbeck AR, Schatzkin A, Abnet CC (2011) Association between smoking and risk of bladder cancer among men and women. JAMA 306(7): 737-745.

Gray R (1988) A class of K-sample tests for comparing the cumulative incidence of a competing risk. Ann Statist 16(3): 1141-1154.

Inman BA, Tran VT, Fradet Y, Lacombe L (2009) Carcinoma of the upper urinary tract: predictors of survival and competing causes of mortality. Cancer 115(13): 2853-2862.

Jemal A, Bray F, Center MM, Ferlay J, Ward E, Forman D (2011) Global cancer statistics. Cancer J Clinicians 61(2): 69-90.

Johnson EK, Daignault S, Zhang Y, Lee CT (2008) Patterns of hematuria referral to urologists: does a gender disparity exist? Urology 72(3): 498-502; discussion 502-3.

Linton KD, Rosario DJ, Thomas F, Rubin N, Goepel JR, Abbod MF, Catto JW (2012) Disease specific mortality in patients with low risk bladder cancer and the impact of cystoscopic surveillance. J Urol 189(3): 828-833.
Lughezzani G, Sun M, Shariat SF, Budaus L, Thuret R, Jeldres C, Liberman D, Montorsi F, Perrotte P, Karakiewicz PI (2011) A population-based competing-risks analysis of the survival of patients treated with radical cystectomy for bladder cancer. Cancer 117(1): 103-109.

Mayr R, May M, Martini T, Lodde M, Comploj E, Pycha A, Strobel J, Denzinger S, Otto W, Wieland W, Burger M, Fritsche HM (2012) Comorbidity and performance indices as predictors of cancerindependent mortality but not of cancer-specific mortality after radical cystectomy for urothelial carcinoma of the bladder. Eur Urol 62(4): 662-670.

Messing EM, Madeb R, Feng C, Stephenson L, Gilchrist KW, Young T, Gee J (2009) Grade and stage at presentation do not predict mortality in patients with bladder cancer who survive their disease. J Clin Oncol 27(15): 2443-2449.

Moore KT (1995) Establishing a new department of urology: an integrated system for national health service and private care. Br J Urol 76(6): 683-685.

Mungan NA, Aben KK, Schoenberg MP, Visser O, Coebergh JW, Witjes JA, Kiemeney LA (2000) Gender differences in stage-adjusted bladder cancer survival. Urology 55(6): 876-880.

Nielsen ME, Shariat SF, Karakiewicz PI, Lotan Y, Rogers CG, Amiel GE, Bastian PJ, Vazina A, Gupta A, Lerner SP, Sagalowsky AI, Schoenberg MP, Palapattu GS (2007) Advanced age is associated with poorer bladder cancer-specific survival in patients treated with radical cystectomy. Eur Urol 51(3): 699-706; discussion 706-8.

Noon AP, Pickvance SM, Catto JW (2012) Occupational exposure to crack detection dye penetrants and the potential for bladder cancer. Occup Environ Med 69(4): 300-301.

Otto W, May M, Fritsche HM, Dragun D, Aziz A, Gierth M, Trojan L, Herrmann E, Moritz R, Ellinger J, Tilki D, Buchner A, Hofner T, Brookman-May S, Nuhn P, Gilfrich C, Roigas J, Zacharias M, Denzinger S, Hohenfellner M, Haferkamp A, Muller SC, Kocot A, Riedmiller H, Wieland WF, Stief CG, Bastian PJ, Burger M (2012) Analysis of sex differences in cancer-specific survival and perioperative mortality following radical cystectomy: results of a large German multicenter study of nearly 2500 patients with urothelial carcinoma of the bladder. Gend Med 9(6): 481-489.

Palou J, Sylvester RJ, Faba OR, Parada R, Pena JA, Algaba F, Villavicencio H (2012) Female gender and carcinoma in situ in the prostatic urethra are prognostic factors for recurrence, progression, and disease-specific mortality in T1G3 bladder cancer patients treated with bacillus CalmetteGuerin. Eur Urol 62(1): 118-125.

Rink M, Fajkovic H, Cha EK, Gupta A, Karakiewicz PI, Chun FK, Lotan Y, Shariat SF (2012) Death certificates are valid for the determination of 
cause of death in patients with upper and lower tract urothelial carcinoma. Eur Urol 61(4): 854-855.

Scrucca L, Santucci A, Aversa F (2007) Competing risk analysis using R: an easy guide for clinicians. Bone Marrow Transplant 40(4): 381-387.

Sheffield City Council (2012) Population Estimates, http:// www.sheffield.gov.uk/your-city-council/sheffield-profile/population-andhealth/population-estimates.html, accessed 6 April 2012.

Sturgeon SR, Hartge P, Silverman DT, Kantor AF, Linehan WM, Lynch C, Hoover RN (1994) Associations between bladder cancer risk factors and tumor stage and grade at diagnosis. Epidemiology 5(2): 218-225.

Thomas F, Noon AP, Rubin N, Goepel JR, Catto JW (2013) Comparative outcomes of primary, recurrent, and progressive high-risk non-muscleinvasive bladder cancer. Eur Urol 63(1): 145-154.

Thomas F, Rosario DJ, Rubin N, Goepel JR, Abbod MF, Catto JW (2012) The long-term outcome of treated high-risk nonmuscle-invasive bladder cancer: time to change treatment paradigm? Cancer 118(22): 5525-5534.

Walters S, Rachet B, Westlake S (2009) Cancer Survival, England, Patients Diagnosed 2001-2006 and Followed Up To 2007: One-Year and Five-Year Survival for 21 Common Cancers, by Sex and Age. Office for National Statistics: London, UK.

Youssef RF, Lotan Y (2011) Predictors of outcome of non-muscle-invasive and muscle-invasive bladder cancer. Scientific World J 11: 369-381.

This work is published under the standard license to publish agreement. After 12 months the work will become freely available and the license terms will switch to a Creative Commons AttributionNonCommercial-Share Alike 3.0 Unported License.

Supplementary Information accompanies this paper on British Journal of Cancer website (http://www.nature.com/bjc) 